\title{
Vision, Touch and Feminist Epistemology
}

\author{
Elizabeth Walden
}

\begin{abstract}
La différence entre la vision et le toucher, la distance et la proximité, est cruciale pour comprendre le rôle des sens dans la pensée et la pratique orientales. Par conséquent, le renversement de la hiérarchie établie entre la vision et le toucher (c.-à-d. la prédominance de la pensée sur la vision) n'altérerait pas vraiment l'ordre politique qui dépend de cette différence. Walden examine cette idée par le biais du film tout à fait tactile The Thin Red Line (Terrence Malik, 1998) et en arrive à la conclusion que nous avons besoin d'une épistémologie féministe qui nous aide à penser les sens dans leur dimension humaine unifiée.
\end{abstract}

When we begin to call into question the hegemony of vision within art and culture, we are at the same time by implication drawing into question our understanding of aesthetics itself and the relation of aesthetics to philosophy and to politics. The idea that aesthetics pertains particularly to art and, hence, to a circumscribed type of practice and experience, depends upon the neat compartmentalization of aesthetic experience, knowledge, and politics, which characterizes modernity. Art provides a safe realm within which to experience affect and engage sensuous particularity. Philosophy can then, in contradistinction to art, conceive of its relation to its object as one of rational comprehension free of the traces of affect and the sensuous. This neat division of labor in turn provides a basis for the legitimation of the modern nation state, which deploys a rhetoric of autonomy and rational participation while mobilizing an ideology which produces cohesion through affect and the sentimental attachment to national identity (Eagleton).

The hegemony of vision plays a significant role in the production and maintenance of this condition. Affect and sensuous particularity are experienced in the realm of art, but only at a contemplative distance. Philosophy, or rational comprehension more generally, also operates on the basis of analogy with vision. But, of course, like the eye itself which sees but does not see itself seeing, the Western tradition has mistaken its construction of a transcendental perspective for an access to an unmediat- 
ed comprehension, if not of the world, at least of consciousness or thinking itself. Detachment, distance, objectivity recur at all levels of modern constructions of art, philosophy and politics, and function as the principles of disavowal for everything that is done in their names.

To propose, then, to discuss the senses, as this special issue of Tessera does, is to involve ourselves inevitably in deeply complex political, philosophical and aesthetic issues. Indeed, the very existence of this issue already implies a critique of our culture's traditional sensory hierarchies and metaphors. The recognition of the various ways in which vision is affirmed at the expense of the other senses in the West draws attention to the body as the site of our engagement with the world, and the senses as powerful figures for understanding that engagement. This gesture itself responds to a patriarchal tradition that values detachment, distance, and objectivity with a recognition that the latter are possible only in the context of connection, proximity, and material participation: this is to respond to a model based on analogy with sight, with one based on analogy with touch.

The situation is much more complex, however. Sight and touch form a unique sensory couple: "the sense of touch had been an integral part of classical theories of vision in the seventeenth and eighteenth centuries" and while the relationship of vision to touch becomes increasingly tenuous in the nineteenth and twentieth centuries, the patterns of distance and proximity that their relationship suggests remain operative throughout modernity (Crary 19). The tactile is the silent partner of vision, helping to legitimate its hegemony even as it is ideologically disavowed. At the same time, however, as the repressed, the tactile has provided the model for a radical response to the culture of ocularcentrism. The immediacy and implicit agency of the tactile threaten the detachment and passivity upon which ocularcentric society depends.

Given this dual character of the tactile, however, we need to be suspicious of our tradition's opposition between vision and touch and the way that this opposition makes the tactile appear to be a seductive alternative to the hegemony of vision. We are in the midst of a time of the disordering of the senses, which presents an opportunity to produce a politics of scale, which in turn recognizes the body as the fragile locus of our relation to the world and to others. The danger is that our exploration of the proximate will generate a new paradigm of power, which extrapolates from embodied experience to produce a metaphysics of proximity, that would replace ocularcentrism with its tactile equivalent without ever drawing 
into question the way in which they both idealize and detach the sensory apparatus from the human/animal body for ideological purposes. We need, then, not to critique vision, but to redeem it, as we explore how consciousness of the sensorium changes the ways we understand ourselves in the world.

It is this tension between the senses per se and their ideological use which necessitates my moving between the terms "vision" and "touch" to the more generic terms "distance" and "proximity." For these latter represent the way in which the senses are extrapolated and idealized in order to play an ideological role. So, for instance, to understand the ideological role of vision in modernity is to understand it as a principle of distance, detachment, and objectivity, even though human vision does not attain these conditions in its embodied sensory form.

In what follows I want to say some more about the role of the proximate in modern society and what I have called its dual character and, then, with reference to Terrence Malick's film The Thin Red Line, to talk about the way in which even the tactile can become a metaphysical principle, if not brought into dialectical relation with vision. While Malick's film presents a gorgeous depiction of the tactile dimension of experience, his occlusion of the female and his circumscribed context of war underscore the necessity of bringing feminist epistemology to bear upon any consideration of the senses.

The most powerful critical description of the ocularcentric society is still that given to us by the Situationists some thirty-plus years ago. As Guy Debord describes it, this society is one produced through a process of "separation," which takes what is proximate to our experience and reconstructs it at a distance as a spectacle for us to consume. "Everything that was directly lived," he writes, "has moved away into a representation" (1). Our own lives and the pleasures of our bodies are expropriated from us and sold back to us as consumer products.

What Debord realized, however, is that this process of separation results in the destruction of distance. As he writes, "the spectacle obliterates the boundaries between self and world by crushing the self besieged by the presence-absence of the world and it obliterates the boundaries between true and false by driving all lived truth below the real presence of fraud ensured by the organization of appearance" (219). The distancing that is the spectacle allows that which seems most distant, most detached from our own experience, to take root in our very bodies as our "lived truth." Hence, the intense visualization of contemporary societies depends upon 
a covert proximity for their legitimation. The spectacle entrances us while nudging our bodies toward a certain kind of material appropriation of a commodified world. This pattern is repeated within the Western conception of reason more generally, wherein a rhetoric of rationalism with its objectivity and detachment and metaphors of sight, disavows affect, emotion, the body, the erotic, etc., as irrational. And yet it is precisely the mobilization of these so-called irrational elements of human life through ideology that secures the rationalist order. Because proximity is officially disavowed, it is always in danger of returning as the monstrous other of reason. Irrationalism is the shadow of rationalism and its alibi for those moments when the repressed proximate erupts into the smoothly functioning world of distance and objectivity.

So proximity has an ideological function in modernity, but it is also, as Debord reminds us, what the society of the spectacle has stolen from us. It is lived experience, our own embodied immediacy, and because it is the repressed or invisible factor in our tradition, it is a powerful and destabilizing challenge to it.

Art is particularly significant in exploring this challenge because it is where "the human sensorium" can still be engaged; it provides a model for experience in general. This is why Walter Benjamin finds, what were for him the new mass media, especially film, promising - they can bring sensuous experience, which has been compartmentalized within the fine arts, to a mass audience. They bring perception beyond the contemplative, the merely optical, and make possible a "tactile appropriation" of life. $\mathrm{He}$ writes,

By close-ups of the things around us, by focusing on hidden details of familiar objects, by exploring commonplace milieus under the ingenious guidance of the camera, the film, on the one hand, extends our comprehension of the necessities which rule our lives; on the other hand, it manages to assure us of an immense and unexpected field of action. (236)

Childhood also presents an important model of the tactile for Benjamin. Before we are trained into a consumer culture that says "Look, but don't touch," our engagement with the world moves easily between looking and touching. What Benjamin finds in the child's consciousness is the connection between perception and action that is the mark of a revolutionary consciousness in adults. According to Susan Buck-Morss, "Children's cog- 
nition had revolutionary power because it was tactile, and hence tied to action, and because rather than accepting the given meaning of things, children got to know objects by laying hold of them and using them creatively, releasing from them new possibilities of meaning" (264). Proximity provides "a mode of cognition involving sensuous, somatic, and tactile forms of perception; a non-coercive engagement with the other that opens the self to experience, but also, in a darker vein, 'a rudiment of the ... powerful compulsion to become and behave like something else" (Hansen 329-30). So while the tactile is a powerful destabilizing factor in a world of hegemonic vision, it produces a troubling metaphor for our relation to the world and others. The loss of self, ecstatic fusion, the child's easy transition from seeing to appropriation (and often then digestion) seems a limited model of relation in a world in which appropriation is an all too familiar and all too violent form of engagement.

The seductions and the dangers of the tactile as an alternative paradigm are beautifully articulated in Terrence Malick's 1998 film The Thin Red Line. The film is virtually a Benjaminian primer on the recovery of the sensorium. Although the action takes place in wartime, the camera, along with our protagonist, continually directs our attention away from the spectacle and fascination of war and the mentality that engenders it toward the small details of sensuous life that war destroys or renders invisible. During lulls in battle we hear the ambient sounds of nature; the camera makes us witness the gorgeous play of light and wind in a glade that will soon become a killing field. We see in detail the effects on flora and fauna of the detached thinking that perpetuates war. We even hear the silent and repressed dialogues of individual men who are tortured by the brutality of their own actions and experience. This lush film reminds us of the planet that our vision is so blindly destroying; it reminds us of the value of play and sensuality; it reminds us of our common human bond.

But there is something profoundly disturbing about the alternative that the film suggests: namely the tactile paradigm's comfortable coexistence with war. Granted the "new man" (Pvt. Witt, played by Jim Caviezel) the film presents to us harbors no hatred for the enemy and would prefer to play and flirt endlessly with the tribal peoples whose way of life is being destroyed by war. But he has no answer to it; its logic does not exist for him. He is represented as a man who has "seen another world," a saint, a stranger. This new man of proximity belongs to what Michel Maffesoli calls "the time of the tribes." He accepts his platoon as his family. And 
while this leads to a laudable sense of responsibility, love, and caring for his brothers, it also makes him into the perfect soldier: courageous and willing. His example suggests two mutually exclusive orders: that of distance, vision, and war, which we cannot help but participate in, but whose values we must not embody; and that of the tactile, for which war is a troubling fact, a fact which nevertheless bears little upon the responsibilities and delights of immediacy. But the celebration of the proximate presents no new alternative; this is the false choice modernity has always presented us: affect and sensuous particularity are again circumscribed so that the hegemony of vision, represented here by war, can continue unimpeded. In this case, sensuous particularity is not compartmentalized in art, but becomes part of a way of life that is nevertheless compatible with war and global exploitation.

It is at this apparent dead-end that feminist epistemology can come to our aid. In particular, I have in mind the work of Dorothy Smith who, while concerned primarily with theorizing sociological method, develops a feminist epistemology which will allow us to negotiate these issues of distance and proximity. Smith draws upon the work of Alfred Schutz and others who suggest that there are different cognitive domains that structure our realities. But whereas Schutz describes two alternative realities, a paramount reality and the domain of science, Smith describes an abstracted mode of science that is always located within the world of local and material actualities, but which implicitly disavows this location (84-85). Her model, then, is not one which opposes distance and proximity, but one which explains the possibility of distance through its relation to proximity.

A "conceptual mode of action" (Smith 81) that transcends and neglects the local, the material, the bodily is promoted by our society at the expense of the proximate. It is still largely women's work to attend to the details of everyday life and to "facilitate men's occupation of the conceptual mode of action" (83). And this is true even though women are not excluded from the conceptual mode of action. This means, however, that given our social organization, women occupy two distinct and often conflicting cognitive spaces and, as a result, according to Smith, have a bifurcated consciousness. For our purposes this means that women must continually negotiate between distance and proximity. The bifurcation prevents the clean entry into the space of abstracted rationalistic explanation that transcends the particularity of locality and bodily existence. Smith's epistemology 
embraces this bifurcation and thereby insists that the cognitive mode of action is always already embedded within the local and the material. She writes,

Beginning from the standpoint of women locates a subject who begins in a material and local world. It shows the different cognitive domains structuring our realities ... as a bifurcation of consciousness, with a world directly experienced from oneself as center (in the body) on the one hand and a world organized in the abstracted conceptual mode, external to the local and particular places of one's bodily existence. The abstracted mode of the scientific province is always located in the local and material actualities. . . The organization that divides the two becomes visible from this base. It is not visible from within the others. (84-85)

It is perhaps no accident that women are relegated to men's fantasies in The Thin Red Line. They serve in the film as part of what exposes the role of the proximate in the lives of these soldiers: these men remember women's bodies, the flow of their dresses, their smiles, the immediacy of a life left behind, but which gives meaning to their present. The only words we hear from women are in letters to and flirtations with men; they seem to bear no relation to this devastating war. Arguably, First Sergeant Welsh (Sean Penn) disrupts the duality of distance and proximity that the film portrays. Penn despises those above him in the chain of command, who know nothing of the conditions on the ground, and he has a begrudging respect for "the new man," whom he nevertheless hopes to reform. But Welsh is crushed by his position, reduced to cynicism and resignation, which are the only responses to war that the battlefield seems to allow him.

But Smith's alternative is not one of cynicism and resignation; it is nothing short of a radical restructuring of human knowledge and, we can extrapolate, the insistence upon the redemption of all the human senses. As I argued in the beginning, our ability to thematize the role of senses in modernity suggests that the dominant sensory hierarchies are loosening. This signals a moment of possibility, but it also suggests an emerging order in which vision does not predominate. The society of the spectacle, which trained its citizens to "look, but don't touch," has learned to draw the entire sensorium into its maw and encourage the vestigial child in all of us to emerge. New interactive technologies like video games give us 
virtual bodies to inhabit and direct, hypertext makes the practice of reading into a very tactile three-dimensional experience. A whole range of new age products exists to help us explore our sensorium in private. Indeed, we seem to have entered a new age of play, one which allows for the exploration of all our senses, but in a way whose destabilizing potential often seems already recuperated. This means that the tactile itself will not provide an alternative paradigm. A new metaphysics of the tactile will just cohabitate with or recapitulate the problems of ocularcentrism. Instead, we need to learn from our senses to refuse to extrapolate from our senses. More fundamentally than new sensory hierarchies, we need new models of reason and relation to the world. Then, perhaps, our sensory experience will change as well. Perhaps we will discover that vision, too, has a proximate character and that we can feel at a distance, that distance and proximity are not in vexed opposition to one another, but together characterize our relation to the world and to others.

\section{Works Cited}

Benjamin, Walter. "The Work of Art in the Age of Mechanical Reproduction." Illuminations: Essays and Reflections. New York: Harcourt, Brace and World, 1968. 217-51.

Buck-Morss, Susan. The Dialectics of Seeing: Walter Benjamin and the Arcades Project. Cambridge: MIT P, 1997.

Crary, Jonathan. Techniques of the Observer. Cambridge: MIT P, 1998.

Debord, Guy. The Society of the Spectacle. Detroit: Black and Red, 1983.

Eagleton, Terry. The Ideology of the Aesthetic. Cambridge: Basil Blackwell, 1990.

Hansen, Miriam. "Benjamin and Cinema: Not a One-Way Street." Critical Inquiry (Winter 1999): 306-43.

Maffesoli, Michel. The Time of the Tribes. London: Sage, 1996.

Malick, Terrence, dir. The Thin Red Line. Perf. Sean Penn, Adrian Brody, James Caviezel, Ben Chaplin, George Clooney, John Cusack, Woody Harrelson. Fox, 1998.

Schutz, Alfred, and Thomas Luckmann. The Structures of the Lifeworld. Evanston: Northwestern UP, 1973.

Smith, Dorothy. The Everyday World as Problematic: A Feminist Sociology.

Boston: Northeastern UP, 1987. 